\title{
Eventos adversos pós-vacinais e resposta social
}

\section{Vaccine adverse events and social response}

\author{
Reinaldo Menezes Martins \\ Presidente do Conselho Acadêmico da Sociedade Brasileira de Pediatria; integra o \\ Comitê Técnico Assessor em Imunizações do Ministério da Saúde \\ Av. Erico Veríssimo 430/102 \\ 22621-180 Rio de Janeiro — RJ Brasil \\ reinaldomm@ig.com.br \\ Maria de Lourdes de Souza Maia \\ Coordenadora-geral do Programa Nacional de \\ Imunizações, da Secretaria de Vigilância em Saúde, \\ do Ministério da Saúde \\ clourdes@funasa.gov.br
}

MARTINS, R. M. e MAIA, M. de L. de S.: 'Eventos adversos pós-vacinais e resposta social'. História, Ciências, Saúde — Manguinhos, vol. 10 (suplemento 2): 807-25, 2003.

A grande maioria das polêmicas públicas relativas a hipotéticos malefícios provocados pelas vacinas é extensão de controvérsias e discussões que surgem no próprio meio médico. Exemplos são os malefícios do mercúrio contido em várias vacinas, como a tríplice viral (MMR), provocando doença inflamatória intestinal e autismo; a vacina contra hepatite B e esclerose múltipla; o vírus SV40 em vacinas contra poliomielite e câncer; a transcriptase reversa em células de embrião de pinto e riscos de infecção por retrovírus; vacinas como causa de asma, diabetes insulinodependente. Em algumas situações houve nítido prejuízo para a saúde da população, como aconteceu na Inglaterra após noticiários alarmantes sobre os riscos da vacina tríplice DTP na década de 1970 e, mais recentemente, com a vacina tríplice viral, contra sarampo, caxumba e rubéola, também na Inglaterra, e a vacina contra hepatite B, na França. Além disso, grupos ativistas contrários à vacina veiculam notícias alarmantes através dos meios de comunicação, especialmente pela Internet. Beneficiam-se dessa situação pessoas e advogados que, com ou sem fundamento científico para as suas alegações, buscam indenizações milionárias, o que tem causado malefícios para a população, principalmente em países como os Estados Unidos, pelo aumento no custo das vacinas, para fazer frente aos processos judiciais, e pela desistência de produção por várias empresas, contribuindo para crises de disponibilidade das vacinas. O Programa Nacional de Imunizações do Brasil tem tido êxito em lidar com os aspectos públicos dos eventos adversos, através da capacitação dos profissionais de saúde que atuam no setor, tanto nos aspectos técnicos como na comunicação social.

PALAVRAS-CHAVE: vacinas, eventos adversos pós-vacinais, reação social.

MARTINS, R. M. e MAIA, M. de L. de S.: 'Vaccine adverse events and social response'. História, Ciências, SaúdeManguinhos, vol. 10 (supplement 2): 807-25, 2003.

Most public debate surrounding the hypothetical adverse effects of vaccines is an extension of the polemics, controversies, and discussions that have arisen within the medical field itself. Examples include the adverse effects of the mercury contained in a number of vaccines, such as the one against measles-mumps-rubella (MMR), which can cause inflammatory bowel disease and autism; the link between the hepatitis B vaccine and multiple sclerosis; the polio vaccine, the SV4O virus, and cancer; reverse transcriptase in chicken embryo cells and the risk of infection by retrovirus; and vaccines as a cause of asthma and insulin-dependent diabetes. In some cases, the public bealth has clearly been harmed-in England, for instance, when alarming reports circulated about the risks of the DTP vaccine in the 1970 s or, more recently, involving the MMR vaccine, likewise in England, and the vaccine against bepatitis B, in France. Groups of activists against vaccines have also spread alarming stories through the media, especially the internet. The ones who gain from this situation are the people and lawyers who sue for millions in damages, whether or not their allegations have any scientific basis. This has brought further problems for the public at large, especially in countries like the United States, with the cost of vaccines rising to cover the cost of lawsuits and with a number of companies halting their vaccine production, thus contributing to crises of vaccine availability. Brazil's National Immunization Program has been successful in dealing with the public aspects of adverse events by training the bealth professionals working in this sector, not just in technical aspects but also in social communication.

KEYWORDS: vaccines, vaccine adverse events, social reaction. 


\section{Contexto histórico}

A descoberta e o desenvolvimento das primeiras vacinas implicaram riscos, exigiram grande coragem e só foram possíveis graças a um contexto histórico no qual as epidemias provocavam terror entre as populações. Os exemplos reproduzidos a seguir são referentes a epidemias de varíola no Brasil e ilustram bem essa situação:

Curitiba, 1838. Toda vez que morre um doente toca o sino da igreja. A população fica apavorada e o som dos sinos amplifica o terror, especialmente dos que estão doentes. O vereador Álvaro Loureiro propõe que se proíbam os dobres da igreja, em benefício dos enfermos.

Cuiabá, 1867. A epidemia acelerou-se por casas, ruas e travessas, e finalmente toda Cuiabá estava assolada, vivendo sob o fantasma da varíola. Não demorou a surgir o pânico na cidade, com o morbo multiplicando as suas vítimas, quando os cemitérios foram poucos para recolher os que sucumbiam. ... Mais de cem vítimas por dia (Macedo, 1974).

A população, tomada de pânico, procurava fugir da cidade, mas a varíola alastrava-se pelo interior. Segundo Clovis Correia da Costa, os proprietários do interior defendiam-se, isolando-se de qualquer contato com vizinhos e refugiados, botavam escravos armados nas estradas, com ordem de fuzilar aqueles que tentassem violar o isolamento. Assim descrevia Estêvão de Mendonça: "Os corpos eram conduzidos em carroças, seminus, numa promiscuidade irreverente, e assim atirados em valas. Essa medida por fim tornouse insuficiente e não raro foram os cadáveres arrastados por cães famintos e até cremados aos montões" (Souza, 1972).

Fortaleza, 1878. Os jornais publicavam, diariamente, as listas e o número de enterramentos. Somente em dezembro de 1878 foram sepultados, no cemitério da Lagoa Funda, privativo dos variolosos, 14.362 cadáveres. Um média diária de quinhentas pessoas sucumbiam ao flagelo.

Nas praias, para onde alguns doentes iam, aí faleciam e, segundo contavam os jornais, cães esfaimados disputavam pernas e braços (Leal, 1978).

Em circunstâncias semelhantes, é compreensível que Edward Jenner tenha submetido o menino James Phipps, de oito anos, à experiência de inoculação com secreções de cowpox, que, na verdade, foi muito mais a comprovação científica do que já se sabia: a varíola da vaca, inoculada no homem, provocava doença benigna e protegia contra a varíola humana. Embora Jenner tivesse seu trabalho recusado pela Real Sociedade de Ciências de Londres, a partir daí a prática de inoculação com cowpox difundiu-se rapidamente por todo mundo. 
A vacina antivariólica era a pior das vacinas, no que se refere a eventos adversos. Causava febre, às vezes as lesões vacinais se disseminavam e havia, embora raramente, casos de encefalite vacinal. Entretanto, foi com ela, e através de vacinação obrigatória feita casa a casa, que foi erradicada a varíola do mundo.

Quando Louis Pasteur injetou em Joseph Meister, um menino de nove anos, acompanhado da mãe, a vacina anti-rábica, cujos estudos estavam ainda incompletos, assumiu o risco do fracasso e das críticas para evitar a sua morte inexorável, tendo em vista a gravidade das feridas infligidas por cão raivoso. O procedimento vacinal de Pasteur era perigoso, mas, na falta de alternativas, era a melhor opção naquele momento.

Mais recentemente, a poliomielite despertava um grande temor entre as mães. Sendo uma doença que se apresentava inicialmente com características semelhantes às de uma gripe, as consultas médicas às crianças com febre tinham como componente obrigatório e ritual a pesquisa dos reflexos patelares. As mães acompanhavam atentamente o procedimento e, se o reflexo fosse mais difícil de ser provocado, ficavam extremamente ansiosas.

Assim, quando houve o acidente Cutter nos Estados Unidos, episódio traumático, com 192 casos de paralisia provocados pela vacina mal inativada por problema de produção, logo após a correção do problema a população voltou a se vacinar.

O Report of the Committee on the Control of Infectious Diseases, o famoso livro vermelho da Academia Americana de Pediatria, na edição de 1957 (Committee on Infectious Diseases, 1957), recomendava que apenas crianças saudáveis fossem vacinadas. Nos postos de saúde do Brasil, para que a vacinação pudesse ser feita, a consulta com o pediatra era obrigatória. Durante as décadas de 1960 e 1970, uma das principais causas de não-vacinação eram as contra-indicações, a maioria delas por problemas irrelevantes, como tosse sem febre, parasitoses, alergias passadas, presentes ou supostas etc. (Martins, 1996, 1974).

Assim, quando começaram os dias nacionais de vacinação contra a poliomielite, um dos trabalhos que teve de ser feito foi o esclarecimento ao público e aos profissionais de saúde da segurança do procedimento, o que foi bem-aceito, pois nessa época havia cerca de dois mil casos de poliomielite por ano. Após os dias nacionais de vacinação, em junho e agosto de 1980, houve rápida diminuição do número de casos.

Já nessa época se sabia da existência de casos de poliomielite provocados pela vacina oral. Numa investigação da Secretaria Nacional de Ações Básicas de Saúde, do Ministério da Saúde, foram encontrados 16 casos de poliomielite associados à vacinação, de 1981 a 1983. Em face dos benefícios incontestes da vacinação em massa, esses casos não causaram maior polêmica ou contestação. 
Mais recentemente os Estados Unidos passaram a usar as vacinas inativadas para evitar os poucos casos de pólio vacinal. Produtores de vacinas passaram a oferecer na rede privada a vacina inativada sob a forma de vacina combinada a várias outras, como a DTP acelular, Hib, hepatite B (vacina hexavalente). Passou a haver uma pressão de mercado para a utilização desse tipo de vacina e os casos (1 ou 2) de pólio vacinal que o Brasil tem por ano passaram a ser muito valorizados. Isso motivou a Organização Pan-Americana de Saúde (OPAS) a enviar um documento ao Ministério da Saúde, recomendando não interromper o uso da vacina oral no Brasil, tendo em vista a necessidade de manter e até de melhorar as coberturas vacinais, o que seria impossível com a vacina inativada.

A vacina que tem criado mais problemas de eventos adversos é o componente pertussis das vacinas DTP (tríplice bacteriana, contra difteria, tétano e coqueluche) ou DTP/Hib (quádrupla bacteriana, associando a DTP à vacina contra Haemophilus influenzae do tipo B). Esse componente é sabidamente o responsável pelos eventos adversos, que, embora raramente, podem ser graves.

$\mathrm{Na}$ Inglaterra, um artigo de Kulenkampff et alii (1974), descrevendo 36 casos de doença neurológica grave após a vacinação DTP, sem que tivesse sido estabelecida relação causal indiscutível, deu margem a noticiário alarmista na imprensa leiga. Houve queda na cobertura vacinal de 80\% (1974) para 31\% (1978). Em 1977-79 houve grande epidemia de coqueluche, a maior em vinte anos naquele país, com 36 óbitos, cinco mil internações, duzentos casos de pneumonia e 83 de convulsões por coqueluche. Quando a confiança pública na vacina foi restaurada, com novo aumento de cobertura vacinal, houve uma queda correspondente na incidência da doença e do número de mortes (Ministério da Saúde, 1998).

No Brasil, entre outros eventos que causaram impacto público negativo no que se refere a eventos adversos após campanhas, foram marcantes os surtos de meningite asséptica após vacinação em massa com vacinas MMR com a cepa Urabe em Salvador (Dourado et alii, 2000), Leningrad-Zagreb no Rio Grande do Sul (da Silveira et alii, 1997), Mato Grosso e Mato Grosso do Sul (da Cunha et alii, 2002) e Curitiba (Arruda et al., 2001).

As campanhas com as vacinas MMR citadas anteriormente foram inegavelmente benéficas para a população, pois foram seguidas de grande diminuição dos casos de caxumba, inclusive de meningite asséptica associada à caxumba. Entretanto, a celeuma pública que ocorreu em alguns lugares, especialmente em Mato Grosso, tornaram questionável a estratégia de vacinação em massa com as cepas mais reatogênicas, em especial a Leningrad-Zagreb.

Curiosamente, as cepas Urabe e Leningrad-Zagreb foram utilizadas em campanhas em vários estados e somente em alguns deles houve repercussão pública de problemas relacionados à meningite asséptica. 
Isso se deve a vários fatores, como adequada informação aos profissionais de saúde e à população dos possíveis eventos adversos e, principalmente, à conduta médica diante desses casos. Em muitos serviços médicos a conduta foi conservadora e expectante, levando em conta não somente os achados do liquor, mas também o estado geral do paciente; em outros, foi mais agressiva, com internação mais longa e repetição de punções lombares, levando à lotação de enfermarias com pacientes com meningite asséptica, provocando grande comoção pública.

Editorial publicado no International Journal of Epidemiology (Fullerton et al., 2002) comenta diversos aspectos da discussão sobre a utilização das diversas vacinas contra caxumba, entre os quais o custo. A MMR preparada com cepa Urabe custa um dólar, enquanto que com a cepa Jeryl Lynn custa dois dólares e meio. A Organização Mundial de Saúde (OMS) publicou documento sobre o assunto em que, embora reconhecendo que certas cepas de vacina contra caxumba podem ter maior risco de provocar meningite asséptica, todas são aceitáveis para uso em programas de imunização (World Health Organization, 2001).

Uma situação repetitiva é a de eventos adversos em associação temporal com a vacinação, mas sem relação causal, especialmente eventos neurológicos, como a síndrome de West, cuja manifestação inicial ocorre entre três e nove meses de idade, o que coincide com a aplicação de muitas vacinas. Em geral, acusa-se a vacina DTP (vacina tríplice contra difteria, tétano e pertussis) de ser a responsável pela síndrome, o que não corresponde à realidade. Alguns casos de síndrome de West em associação temporal com a vacinação DTP têm criado sérios problemas para os programas de imunização, pelo impacto emocional que provocam na família e na sociedade, inclusive no Brasil (Melchior, 1977; Bellman et alii, 1983; Fukuyama et alii, 1977).

\section{Momento crítico}

Em situações de epidemias ou grande incidência de doenças graves, como varíola, difteria, tétano, coqueluche, poliomielite etc., os riscos associados às vacinas tendem a ser aceitos com uma certa resignação. Mas, graças ao sucesso dos programas de imunização, essas doenças desapareceram (varíola, poliomielite e talvez o sarampo) ou apresentam agora baixas incidências, como difteria, tétano e coqueluche. As mães já não as temem; possivelmente muitas delas sequer as conhecem.

Por outro lado, a análise clássica de risco versus benefício comparava as vacinas com as doenças, e o saldo era amplamente favorável às vacinas. Agora surge uma nova questão: as vacinas menos reatogênicas do que as clássicas, que chegaram ao mercado através de empresas privadas, infelizmente são de alto custo e de produção restrita a poucos laboratórios produtores. 
Em 1992, teve início a implantação do Sistema de Vigilância de Eventos Adversos Pós-Vacinação do Ministério da Saúde (SVEAPV). Em 1998 foi publicado e distribuído amplamente o Manual de vigilância epidemiológica dos eventos adversos pós-vacinação (Ministério da Saúde, 1998). Os profissionais de saúde que trabalham nos postos de saúde foram treinados em relação aos eventos adversos, seu diagnóstico e conduta. Assim, há uma percepção muito maior dos riscos inerentes às vacinações.

O SVEAPV é um sistema passivo, semelhante ao utilizado nos Estados Unidos, cuja sigla é VAERS (Vaccine Adverse Event Reporting System). É um sistema com muitas limitações, como subnotificação, notificação de casos relacionados temporalmente mas sem associação causal, sujeito a influências que afetam sua sensibilidade etc. Um dos pontos mais negativos desse sistema é, de certa forma, dar credibilidade a eventos com associação temporal mas sem relação causal com as vacinações.

Atingimos agora um momento crítico no programa de imunizações do Brasil, em que as doenças assustam menos e ganham relevo os eventos adversos, o que já é um fenômeno bem estudado (Chen, 1999).

Algumas vacinas menos reatogênicas foram lançadas no setor privado de imunizações. Como exemplo, temos a DTP com o componente pertussis acelular, que é uma vacina que inclui antígenos purificados de Bordetella pertussis, em vez de bactérias inteiras destoxificadas por formaldeído, como é feito há décadas (vacina DTP clássica). Algumas dessas vacinas acelulares conferem proteção semelhante à DTP clássica, mas com muito menos eventos adversos. Por que não as utilizar rotineiramente no Brasil?

A primeira razão é que não existe disponibilidade dessa vacina para atender à demanda do Programa Nacional de Imunizações (PNI). Além disso, são produtos protegidos por patentes, produzidos por poucos laboratórios multinacionais, que não desejam repassar essa tecnologia, e de alto preço.

Em conseqüência de exigências cada vez maiores em relação à qualidade e à segurança, bem como a alternativas comercialmente mais favoráveis dentro do mercado farmacêutico, muitas empresas públicas e privadas deixaram de produzir vacinas. Assim, há atualmente uma vulnerabilidade de abastecimento, especialmente em relação aos novos produtos.

Nos Estados Unidos, cinco das oito vacinas aplicadas regularmente são fornecidas, cada uma delas, por um único produtor. Em 1967, havia 26 produtores de vacinas; agora são apenas 12, dos quais quatro produzem quase todas as vacinas distribuídas. Esses quatro são: Merck e Wyeth (EUA), Aventis Pasteur e GlaxoSmithKline (Europa).

Nos Estados Unidos, cinco das oito vacinas aplicadas regularmente são fornecidas, cada uma delas, por um único produtor. Em 1967 havia 
26 produtores de vacinas; agora são apenas 12, dos quais quatro produzem quase todas as vacinas distribuídas. Esses quatro são: Merck e Wyeth (EUA), Aventis Pasteur e GlaxoSmithKline (Europa). Em 2000 começou a haver escassez de vacinas, que se acentuou em 2001 (cinco vacinas em escassez). Isso implicou modificar o calendário de vacinações e adiar vacinações de rotina, resultando em menores coberturas vacinais e aumento no risco de aquisição de doenças. Entre essas vacinas estavam a dT (dupla contra difteria e tétano tipo adulto), DTaP (tríplice acelular), vacina contra pneumococo conjugada, MMR e vacina contra varicela (United States General Accounting Office, 2002). Se isso se dá nos Estados Unidos, é fácil concluir que colocar na rotina do PNI do Brasil todas as novas vacinas, inclusive a DTP acelular, é impossível no momento.

No entanto, o setor privado brasileiro de vacinas, que as vende em clínicas e consultórios particulares, oferece todas essas novas vacinas aos seus clientes. Embora atingindo uma parte pequena da população total do país, esse mercado é muito ativo em promover os seus produtos, tendo como um dos pontos de atração a menor reatogenicidade das vacinas.

\section{Os exageros e distorções}

Internet

A Internet veicula todo tipo de notícia, para o bem ou para o mal. Numa busca rápida, encontrei um documento, datado de 25 de agosto de 1999, que pode ser dado como exemplo de opinião tendenciosa, com ares de credibilidade. Sua autora é Phyllis Schlafly, advogada, apresentada como graduada Phi Beta Kappa da Universidade de Washington, mestra em ciência política da Universidade de Harvard, autora de vinte livros.

O documento veicula várias informações distorcidas, das quais destaco a que diz que, após o recebimento da vacina contra hepatite B, há mais eventos adversos relatados, inclusive 48 óbitos, do que casos notificados de hepatite B em crianças.

Essa é uma leitura equivocada das estatísticas, feita por quem não tem compreensão dos fenômenos biológicos e das limitações do sistema de notificação de eventos adversos, o VAERS, confundindo associação temporal com causalidade.

Afirma também que hoje as crianças recebem 33 imunizações antes de poderem ir à escola, e que os pais estão se perguntando qual é o maior risco, receber as vacinas ou adquirir as doenças.

Informa ainda que o VAERS recebeu 11 mil queixas de pais ou médicos em 1998. Ao apresentarem seus pedidos de compensação por eventos adversos, os pais tiveram de enfrentar uma bateria de 17 advogados veteranos que trabalham em tempo integral no Departamento 
de Justiça. E assim, apenas 1.300, das mais de 5.300 famílias queixosas, conseguiram obter as compensações solicitadas.

Entretanto, em compensação, a Internet divulga informações corretas sobre vacinas e documentos que procuram esclarecer dúvidas sobre a sua segurança, por exemplo, no site do CDC (Estados Unidos - www.cdc.gov), no site da Funasa/MS (Brasil www.funasa.gov.br) e através de outros documentos de sociedades médicas ou até de jornalistas bem informados. (Ver Williamson D. Study www.eurekalert.org/pub-releases/1996-12; The Scientist www.biomedcentral.com/news/20010124/03; Yahoo News http:// uk.news.yahoo.com/030708/80/e3wro.html.)

\section{Mercúrio nas vacinas}

Um dos motivos da crise de abastecimento de vacinas dos Estados Unidos foi a recomendação de retirar o mercúrio (contido no timerosal) das vacinas. Sem o conservante, os fabricantes passaram a ter de fabricar as vacinas em frascos de monodoses. A base factual para essa recomendação é frágil, mas as alegações sobre os riscos do mercúrio como causa de várias doenças, especialmente o autismo, levaram inclusive à sessão pública de questionamento, convocada pelo Senado e a Câmara de Representantes dos Estados Unidos, com a participação de representantes, entre outros, do National Center on Birth Defects and Developmental Disabilities do CDC, do National Immunization Program do CDC, do National Institute of Mental Health, da Autism Society of America, da Autism Coalition, da Cure Autism Now Foundation, sendo estas três últimas organizações não-governamentais, com um total aproximado de oitenta mil membros (Committee on Government Reform, 2002).

O título do documento da investigação é sugestivo: 'A epidemia de autismo - a resposta do National Institutes of Health (NIH) e do CDC (Centers for Disease Control) é adequada?.

Nesse documento, obtido na Internet, o chairman do comitê do Senado, que convocou a reunião, fala do aumento de vinte vezes na incidência de autismo, e que seu neto, após receber as imunizações de rotina, tornou-se autista, tendo atribuído esse evento adverso à toxicidade do mercúrio veiculado pelas vacinas. A mesma acusação foi feita por vários outros participantes.

O timerosal é usado em vacinas há mais de setenta anos, para evitar contaminação por bactérias e fungos. Em 1999, a Academia Americana de Pediatria, o Serviço de Saúde Pública e a Academia Americana de Médicos de Família recomendaram que se retirasse o mercúrio das vacinas por causa da preocupação pública com o assunto (Centers for Disease Control, 2001). Ao mesmo tempo, citavam-se vários estudos conduzidos pelo National Institutes of Health e pelo CDC que não consubstanciavam nenhum evento adverso em função do 
uso de mercúrio nas vacinas. Em particular, que não havia nenhuma evidência, através de vários estudos, que pudesse associar causalmente vacinações e autismo.

A decisão fez com que o início da vacinação contra hepatite $B$ fosse adiado até dois a seis meses de idade em crianças cujas mães fossem HBsAg negativas. Embora fosse recomendado que as crianças cujas mães fossem HbsAg positivas recebessem imediatamente a vacina contra hepatite $\mathrm{B}$, na prática aconteceu que algumas crianças nãoimunizadas contraíram a doença (Kimmel, 2002).

Pichichero (2002) dosou a concentração de mercúrio no sangue, na urina e nas fezes de quarenta lactentes nascidos a termo e que receberam as imunizações de rotina, comparando-as com 21 que receberam vacinas sem timerosal. Verificou que o mercúrio é eliminado rapidamente do sangue para as fezes e que não parece aumentar as concentrações de mercúrio acima de níveis seguros.

Potter (2002) analisa o aparente aumento do autismo. No estudo original de Kanner, publicado em 1943, o autismo era considerado raro, com uma prevalência em torno de duas a quatro por dez mil crianças. Estudos posteriores relataram aumentos anuais na incidência de autismo em crianças. Prevalências de autismo de sessenta por dez mil (1:167), e até maiores, utilizando um critério diagnóstico expandido, foram encontradas. As razões para esse aumento incluem novos critérios diagnósticos, desenvolvimento do conceito de espectro ampliado de autismo, metodologias diferentes utilizadas nos estudos, maior percepção e conhecimento do problema pelos pais e profissionais, o desenvolvimento de serviços especializados ou, até mesmo, a possibilidade de aumento real. Nenhum fator ambiental, inclusive vacinações, foi confirmado como fator etiológico em estudos realizados por investigação científica independente.

Esse é um exemplo de grande tumulto nos programas de imunização, com grande repercussão pública mas de base factual fraca.

No entanto, a polêmica vai continuar. Geier e Geier (2003), analisando a base de dados do VAERS, encontraram aumento de risco relativo de autismo $(R R=6.0)$, retardo mental $(R R=6.1)$ e distúrbios da fala $(R R=2.2)$ em crianças que receberam vacinas DTaP contendo mercúrio, em comparação com as que receberam DTaP sem mercúrio.

\section{Vacina MMR, doença inflamatória intestinal e autismo}

A controvérsia sobre vacina MMR (tríplice viral, contra sarampo, caxumba e rubéola) como causa de doença inflamatória intestinal e autismo começou em 1998, com um estudo realizado no Royal Free Hospital de Londres por Wakefield et alii (1998). Esse estudo avaliou 12 crianças que tinham sido encaminhadas a um serviço de gastroenterologia pediátrica, com história de desenvolvimento normal, e que tiveram perda de habilidades adquiridas, inclusive de 
linguagem, com diarréia e dor abdominal. Os autores relataram que os pais associaram o início dos sintomas com a vacinação MMR em oito das 12 crianças. Todas tinham desde hiperplasia nodular linfóide até úlceras intestinais. Considerou-se que nove das crianças tinham autismo. Wakefield sugeriu que poderia haver uma ligação entre a vacina MMR e o quadro clínico.

Posteriormente, Wakefield publicou um estudo de 25 crianças com autismo, das quais 24 tinham traços de vírus do sarampo no intestino. O Royal Free Hospital publicou uma declaração que apontava fraquezas no estudo.

Outro grupo desse hospital publicou grandes estudos epidemiológicos que não mostraram evidências dessa associação (Taylor et alii, 2002; Taylor et alii, 1999).

Grande estudo epidemiológico realizado na Finlândia (Makela et alii, 2002) não mostrou qualquer evidência de associação entre vacinação MMR e encefalite, meningite asséptica ou autismo. Em outro estudo na Dinamarca (Madsen et alii, 2002), os autores concluíram que as evidências eram contrárias à hipótese de que a vacinação MMR cause autismo.

Essa controvérsia atingiu a população inglesa através de discussões na imprensa leiga. A Sociedade Autística Nacional solicitou mais pesquisas, afirmando que o Departamento de Saúde não havia examinado o assunto adequadamente.

A conseqüência foi perda de confiança na vacina MMR e queda nas coberturas vacinais na Inglaterra, de 93\% para 88\%; em algumas partes do país as coberturas de vacinação MMR chegaram a ficar abaixo de $75 \%$. Desse modo, a Inglaterra está sujeita a novas epidemias de sarampo, caxumba ou rubéola.

\section{Vacina contra hepatite $B$ e esclerose múltipla}

Em 1994, a França acrescentou a vacina contra hepatite B ao esquema vacinal da infância e lançou uma campanha nas escolas, visando principalmente aos adolescentes de 11 e 12 anos. A vacinação se estendeu além desses grupos-alvo. Mais de 75 milhões de doses tinham sido vendidas no final de 1997. Mais de um terço da população da França foi vacinada até 1999. A cobertura vacinal do grupo de 16 a vinte anos chegou a 80\% em 1997.

Graças às notificações de doenças neurológicas que se assemelhavam a exacerbações de esclerose múltipla, doença grave desmielinizante do sistema nervoso central e de etiologia desconhecida, após a vacina contra hepatite B, um programa de fármaco-vigilância foi iniciado em 1994 na França. Até 1998, a situação era a seguinte:

- Os estudos não confirmaram nem negaram o vínculo entre vacina contra hepatite $\mathrm{B}$ e um pequeno aumento de risco de esclerose múltipla. 
- O máximo risco era nenhum para lactentes, menos de 0,3 por cem mil em pré-adolescentes e menos de um em adultos vacinados.

Embora nenhum teste estatístico desse significância ao nível de 0,05, o Ministério da Saúde da França patrocinou um estudo de risco $\mathrm{x}$ benefício para tomar a decisão de continuar ou não a vacinação contra hepatite $\mathrm{B}$, que chegou à conclusão de que não havia razão para questionar a estratégia de vacinação seguida até então. Surpreendentemente, o Ministério da Saúde recomendou a manutenção das estratégias vacinais, mas a vacinação dos adolescentes passou a ser feita, por decisão individual de cada família, em clínicas privadas.

A discrepância entre as conclusões dos estudos de segurança e a interrupção da vacinação nas escolas criou confusão na mídia, no público e na comunidade médica, levando à queda na cobertura vacinal contra hepatite $\mathrm{B}$, que se estendeu à vacina contra hepatite $\mathrm{A}$, mas felizmente não a outras vacinas.

Vários outros estudos, realizados nos Estados Unidos e na Europa, não mostraram evidência de associação entre hepatite $\mathrm{B}$ e doenças desmielinizantes do sistema nervoso central (World Health Organization, 1999).

Estudo da Base de Dados da Europa para Esclerose Múltipla mostrou que a vacinação contra tétano, hepatite B e influenza não aumentou o risco de recaída de esclerose múltipla, pelo menos a curto prazo (Kimmel, 2002).

Grande estudo ainda mais recente de caso-controle, realizado pelo CDC, avaliando a relação entre esclerose múltipla, neurite óptica e vacinações, concluiu que as vacinas contra hepatite $\mathrm{B}$, influenza, tétano, sarampo ou rubéola não estão associadas ao aumento de risco de esclerose múltipla ou neurite óptica (DeStefano, 2003).

\section{Outras situações}

Algumas dúvidas na comunidade médica, que às vezes se estenderam à mídia, gerando ansiedade, foram:

- Vírus SV40, vacinas contra poliomielite e câncer. O vírus SV40 causa infecção benigna em macacos, mas é capaz de induzir tumores em roedores. As culturas de células de rim de macaco utilizadas para cultivo do vírus vacinal da poliomielite na década de 1950 estavam contaminadas com esse vírus. Quando o problema foi descoberto, na década seguinte, passou-se a fazer esse controle e o vírus SV 40 não mais contamina esses meios de cultura.

- Técnicas refinadas de análise molecular encontraram atividade de transcriptase reversa em células de embrião de pinto usadas para preparar vacinas contra sarampo, caxumba e febre amarela. Após extensos estudos realizados pela OMS, foi verificado que essa 
atividade estava ligada a partículas incompletas de retrovírus de origem aviária que não representam risco real para a população humana.

- Vacinação de lactentes e asma. Levantou-se a idéia de que as vacinações na infância podem aumentar o risco de asma, ao direcionar a resposta imune para a produção prioritária de citocinas de tipo Th2, associadas às reações alérgicas. As evidências indicam, entretanto, que essa tendência à produção prioritária de Th2 precede a administração de vacinas, sendo uma característica individual (Chen et alii, 2001).

- Vacina contra rotavírus e invaginação intestinal. A vacina contra rotavírus, causa importante de gastroenterite grave na infância, foi licenciada pela Food and Drug Administration (FDA), dos Estados Unidos, em 31 de agosto de 1998 e é recomendada para a vacinação de rotina na infância. Nos estudos pré-licenciamento, a invaginação ocorreu em cinco de dez mil e cinqüenta e quatro receptores da vacina e em um de 4.633 controles. A diferença não era estatisticamente significativa, mas levou à recomendação de que houvesse vigilância para a ocorrência de invaginação após o licenciamento. De fato, observou-se um aumento nos casos de invaginação intestinal entre os vacinados, o que levou à suspensão da vacina. A decisão da saúde pública americana inviabilizou o uso dessa vacina em países pobres, onde o risco de adoecer e morrer por infecção por rotavírus é muito maior do que o risco da invaginação intestinal provocado pela vacina, o que é um exemplo de que no campo das vacinações as considerações estatísticas e a avaliação de risco x benefício nem sempre preponderam.

— Imunização e diabetes. Foi sugerido que certas vacinas, se dadas logo após o nascimento, diminuiriam a ocorrência de diabetes; por outro lado, se fossem administradas a partir dos dois meses de idade, aumentariam o risco de diabetes de tipo 1 (diabetes grave, insulino-dependente). Essa hipótese se baseava em resultados de experiências em animais de laboratório e em comparações de incidências de diabetes em países com diferentes esquemas vacinais. Estudos rigorosos mostraram, entretanto, que não há relação entre incidência de diabetes de tipo 1 e época de início das vacinações, ou mesmo entre aplicação de qualquer vacina e diabetes de tipo 1 em seres humanos (Chen et alii, 2001).

\section{Litígios}

Processar fabricantes de vacinas e profissionais de saúde tornouse uma indústria rendosa nos Estados Unidos no final da década de 1970 e início da de 1980. 
Um processo judicial marcante foi o de Reyes versus Wyeth, de 1974, em que este laboratório, então produtor de vacina oral contra poliomielite, foi acusado de vender sua vacina para o governo sem que na bula constasse a advertência de que poderia causar paralisia. Como se tratava de uma campanha, em que não havia contato direto entre o médico e o cliente, o laboratório foi responsabilizado (Kitch et alii, 1999).

Quando começaram as campanhas nacionais de vacinação contra poliomielite no Brasil, em 1980, houve quem se lembrasse disso.

Em 1979, a esposa de um diplomata americano, que foi vacinada contra raiva (vacina preparada em embrião de pato) e posteriormente acometida de paralisia, foi indenizada em 469.051 dólares. O marido recebeu mais cinqüenta mil dólares (US Department of Health, Education and Welfare, 1979).

Outro exemplo foi o litígio Toner versus Lederle, no qual o júri condenou o laboratório a uma indenização de 1.131.200 dólares em favor de um receptor de vacina DTP que apresentou posteriormente mielite transversa.

Os advogados passaram a procurar as possíveis vítimas, incitandoas a moverem ações legais. Por causa de litígios, dois dos três produtores de vacinas dos Estados Unidos se retiraram do mercado há aproximadamente trinta anos (Williamson, 1996).

Outra conseqüência foi o aumento de custo das vacinas, em virtude dos processos judiciais. A dose de vacina DTP, por exemplo, que custava 19 centavos de dólar em 1980 passou a custar 12 dólares em 1986 (Kitch et alii, 1999).

O National Childhood Vaccine Injury Act, a lei americana de compensação por eventos adversos pós-vacinais, teve como uma de suas maiores motivações aliviar os fabricantes de vacinas de processos judiciais.

Muitos países desenvolvidos dispõem atualmente de programas de compensação a eventos adversos, com amplitudes variáveis de cobertura (Evans, 1999).

\section{As ações do Ministério da Saúde ante os eventos adversos pós-vacinais}

Enquanto existia grande incidência de doenças imunoevitáveis no Brasil, o PNI e a sociedade organizada tinham as atenções voltadas para o seu controle. Pouco se discutia acerca de segurança de vacinas e sobre os eventos adversos relacionados às vacinações. As décadas de 1980 e 1990 caracterizam-se, pois, pela queda das incidências de doenças evitáveis por vacinação e o início da organização, ainda tímido, de um sistema de vigilância de eventos adversos pós-vacinais. Nesse sentido tiveram importante papel as entidades de classe, através dos seus membros, que compunham o 
Comitê Técnico Assessor em Imunizações e que participaram dinamicamente da elaboração dos primeiros protocolos para investigação de possíveis eventos adversos, em 1992.

Em 1997, um óbito inicialmente atribuído à vacina, ocorrido em um estado do Nordeste, teve grande repercussão na mídia falada e escrita, dando início, talvez pela primeira vez, aos questionamentos sobre alguma das vacinas em uso no setor público. No caso, tratavase da vacina DTP clássica, de células inteiras. Vale ressaltar que no Brasil já estava em uso, no setor privado, a vacina DTP acelular, menos reatogênica. Foi necessário um trabalho intenso e rápido que evitasse o descrédito do programa e, ao mesmo tempo, o risco de ressurgimento de doenças já controladas pelas vacinas.

Algumas providências foram tomadas rapidamente, como investigação de todo e qualquer caso com suspeita de evento adverso pelo nível nacional, elaboração de manual de eventos adversos, seminários de sensibilização para profissionais de saúde nas macrorregiões e, posteriormente, várias capacitações técnicas para médicos e enfermeiros. Era preciso criar uma massa crítica de profissionais com conhecimentos sobre eventos adversos que pudessem dar segurança aos vacinadores e evitar as falsas contra-indicações, por insegurança e medo, de quem está na ponta.

Ainda no final da década de 1990, o Brasil acelerou sua estratégia de controle da rubéola e eliminação do sarampo, com a vacinação em massa e indiscriminada das crianças de um a 11 anos com a vacina tríplice viral, contra sarampo, caxumba e rubéola (MMR). Assim, foi aplicada uma grande quantidade de vacinas em curto espaço de tempo, com algumas das cepas vacinais contra caxumba sendo realmente mais reatogênicas.

Em conseqüência, como já referimos, ocorreram subitamente vários episódios de eventos adversos, e o PNI contratou os serviços de universidades, como o Instituto de Saúde Coletiva, da Bahia, para fazer estudos que avaliassem o problema, o que acabou levando à decisão de suspender o uso de uma das cepas vacinais contra caxumba.

Situações como essas, em que se procurou dar os esclarecimentos à população, seja através da mídia ou das sociedades de classe, foram fundamentais para a consolidação cada vez maior da credibilidade do programa e de uma transição até certo ponto tranqüila entre a era de doenças, seu desaparecimento e a visibilidade de possíveis eventos adversos pós-vacinais.

O PNI passou por vários momentos delicados, como os óbitos associados à vacina contra febre amarela e durante a implantação da vacina contra influenza, com milhares de doses sendo aplicadas numa população antes não trabalhada e que, a partir de 1999, foi vacinada com vigor. 
Outro desafio foi implantar a vacina contra rubéola e sarampo para mulheres em idade fértil, o que provocou temores e necessitou que se intensificasse o trabalho junto aos profissionais de saúde, através da Federação Brasileira de Ginecologia e Obstetrícia. Muitos médicos e demais profissionais de saúde consideravam essas vacinas mais como risco do que beneficio para o feto e o recém-nascido. Fez-se um trabalho de esclarecimento, por meio de folhetos, cartazes e documentos técnicos, junto às associações profissionais. Foram dadas entrevistas em tevês e rádios, procurando-se orientar a população. Os esforços foram mais uma vez coroados de êxito, com mais de 28 milhões de mulheres sendo vacinadas. O Brasil já apresenta queda da incidência de rubéola e, principalmente, da síndrome de rubéola congênita.

É importante que se registre que a Coordenação Geral do Programa Nacional de Imunizações teve o cuidado de preparar seus coordenadores estaduais de imunizações não somente com atualizações técnicas sobre possíveis eventos adversos pós-vacinais, como já relatado, mas também em como atuar junto à mídia, buscando informar e, principalmente, dar sempre o giro positivo. Esclarecer a mídia sempre, buscando espaços e transformando notícias negativas em positivas para o programa, como, por exemplo, comparando o risco das doenças com o benefício, muito maior, das vacinas (giro positivo). Para tanto, a Coordenação Geral do PNI organizou, com a OPS, o curso Trabalhando os Meios de Comunicação. Pôde-se verificar um melhor desempenho dos coordenadores de imunizações junto à mídia, seja por maior freqüência de participações, seja por melhor qualidade de suas intervenções.

Em 2003, o PNI pretende chegar um pouco mais perto das pessoas vacinadas, por meio do vacinador. Está em elaboração, pela Escola Politécnica Joaquim Venâncio, da Fiocruz, uma cartilha sobre eventos adversos pós-vacinais, para o trabalhador de nível médio. Capacitar melhor o vacinador, que é o primeiro a ter contato com os vacinados e que também deverá ser o primeiro a ser procurado em caso de algum evento adverso, é essencial.

No Brasil ainda não temos problemas legais relacionados aos eventos adversos pós-vacinais em grande escala. Um grupo de trabalho do Ministério da Saúde preparou uma proposta de projeto de lei criando um sistema de compensação a eventos pós-vacinais graves, ainda não implementada. A motivação do grupo foi o de justiça social, procurando criar um mecanismo oficial que protegesse os acometidos desses eventos, em que ficasse caracterizada a associação causal com a vacina administrada.

A imprensa, algumas vezes, tem tentado criar um clima de desconfiança contra as vacinas, com notícias ou publicações alarmistas. A atitude do Ministério da Saúde tem sido evitar polêmicas públicas, pois em geral os responsáveis por essas notícias ou publicações buscam sensacionalismo e se alimentam de controvérsias. 
Deve-se reconhecer, entretanto, que no cômputo geral a participação da mídia tem sido exemplar e fundamental para o êxito das ações de imunização.

As coberturas vacinais continuam muito altas, no país como um todo, refletindo a confiança da população no PNI. Alguns eventos, até mesmo graves, como os relacionados à vacina contra febre amarela, não abalaram essa confiança, inclusive, pela maneira transparente com que se lidou com o problema.

É possível, entretanto, que esse panorama mude. Grupos de ativistas contra as vacinas usam e abusam dos meios de comunicação, especialmente da Internet. Em recente apresentação em Brasilia, em reunião dos coordenadores estaduais de imunização, o dr. José Cassio de Moraes apresentou os resultados de um inquérito de cobertura vacinal no município de São Paulo, realizado em 2002. Surpreendentemente, as coberturas vacinais foram mais baixas na classe A, de maior poder aquisitivo, melhor instrução e certamente com maior acesso à Internet.

Se alguns setores da mídia estiverem contribuindo realmente para menores coberturas vacinais em determinados estratos sociais, vai ser necessário melhorar e ampliar a comunicação social relativa às vacinas para que, sem negar os possíveis eventos adversos, se coloque a verdade, isto é, o imenso benefício que as vacinas conferem à grande maioria daqueles que as recebem.

É de se esperar que o debate saudável e democrático sobre riscos e benefícios das vacinações seja temperado pela necessidade de ter prudência e muita responsabilidade diante de questões de tanta relevância para a saúde da população.

\section{REFERÊNCIAS BIBLIOGRÁFICAS}

Arruda, W. O. e

Kondageski, C. 2001

Bellman, M. H.;

Ross, E. M. e Miller, D. L. 1983

National Centers for Disease Control,

Chen, R. T. 1999

Chen, R. T.; De Stefano, F.; Pless, R.; Mootrey, G.; Kramarz, P. e Hibbs, B.

2001
'Aseptic meningitis in a large MMR vaccine campaign (590,609 people) in Curitiba, Parana, Brazil, 1998'. Revista do Instituto de Medicina Tropical de São Paulo. 43:301-2.

'Infantile spasms and pertussis immunisation'.

Lancet, 1:1.031-4.

'Thimerosal Policy Question and Answers'.

Obtido em http://www.cdc.gov/nip/vacsafe/concerns/thimerosal/PolicyQ\&A.htm

'Safety of vaccines'. Em S. A. Plotkin, W. A. Orenstein (eds), Vaccines. $3^{\mathrm{a}^{\mathrm{r}}}$ ed., Filadélfia, Saunders, p. 1145.

'Challenges and controversies in immunization safety'. Infectious Disease Clinics of North America, 15:21-39, vii. 
Committee on

Government Reform 2002

Committee 1957

Da Cunha, S. S.; Rodrigues, L. C.; Barreto, M. L. e Dourado, I.

2002

Da Silveira, C. M.; Kmetzsch, C. I.;

Mohrdieck, R.;

Sperb A. F. e Prevots 2002

De Stefano, F.;

Verstraeten, T.;

Jackson, L. A.;

Okoro, C. A.; Benson, P.;

Black S. B.;

Shinefield, H. R.;

Mullooly, J. P.; Likosky W.

e Chen, R. T.

$$
2003
$$

Dourado, I.; Cunha, S.;

Teixeira, M. G.;

Farrington, C. P.; Melo, A.;

Lucena, R. e Barreto M. L. 2000

Evans, G.

1999

Fukuyama, Y.; Tomori N. e Sugitate, M.

Fullerton, K. E. e

Reef, S. E.

2002

Geier, M. R. e

Geier, D. A

$$
2003
$$

Kimmel, S. R.

$$
2002
$$

Kitch, E. W.; Evans, G. e Gopin R.

1999

Kulenkampff, M.;

Schwartzman, J. S. e

Wilson J.

1974

Leal, V. B.

1978
'The autism epidemic - is the NIH and CDC response adequate?'.

Documento obtido em http://www.gpo.gov/congress/house.

Report of the Committee on the Control of Infectious Diseases. American Academy of Pediatrics.

'Outbreak of aseptic meningitis and mumps after mass vaccination with MMR vaccine using the Leningrad-Zagreb mumps strain'.

Vaccine, 20:1.106-12.

'The risk of aseptic meningitis associated with the Leningrad-Zagreb mumps vaccine strain following mass vaccination with measles-mumps-rubella vaccine, Rio Grande do Sul, Brazil, 1997'.

. International Journal of Epidemiology, 31:978-82.

'Vaccinations and risk of central nervous system demyelinating diseases in adults'. Vaccine Safety Datalink Research Group.

Archives of Neurology, 60:504-9.

'Outbreak of aseptic meningitis associated with mass vaccination with a Urabecontaining measles-mumps-rubella vaccine: implications for immunization programs'. American Journal of Epidemiology, 151:524-30.

'Vaccine injury compensation programs worldwide'. Vaccine, 17: S25-S35.

'Critical evaluation of the role of immunization as an etiological factor in infantile spasms'. Neuropediatrics, 8:224-337.

'Commentary: ongoing debate over the safety of the different mumps vaccine strains impacts mumps disease control'.

International Journal of Epidemiology, 31:983-984.

'Neurodevelopmental disorders after thimerosal-containing vaccines:

a brief communication'. Experimental Biology and Medicine, 228:660-4.

'Vaccine adverse events: separating myth from reality'.

American Family Physician, 66:2.113-20.

'US Law'. Em S. A. Plotkin e W. A. Orenstein,

Vaccines. $3^{\underline{\underline{a}}}$ ed., Filadélfia, Saunders, pp. 1.165-86.

'Neurological complications of pertussis inoculation'.

Archives of Diseases of Children, 49:46-9.

História da medicina no Ceará.

Fortaleza, Secretaria de Cultura, Desporto e Promoção Social, pp. 51-5. 
Macedo, H. B. A variola em Curitiba.

$1974 \quad$ Curitiba, Editora Lítero-Técnica, pp. 18-9.

Madsen, Kreesten 'A population-based study of measles, mumps, and rubella vaccination and

Meldgaard; Hviid, Anders; autism'. New England Journal of Medicine, 347:1.477-82.

Vestergaard, Mogens;

Schendel, Diana;

Wohlfahrt, Jan;

Thorsen, Poul;

Olsen, Jorn e Melbye, Mads

2002

Makela, A.; Nuorti J. P. e 'Neurologic disorders after measles-mumps-rubella vaccination'.

Peltola, $\mathrm{H}$.

2002

Martins, R. M.

1996

Martins, R. M.

1974

Pediatrics, 110:957-63.

Melchior, J. C.

1977

Ministério da Saúde 1998

Pichichero, M. E.;

Cernichiari, E.;

'Oportunidades perdidas de imunização'.

Jornal de Pediatria, 72:3-4.

'Pediatria preventiva'.

Pediatria Moderna, 8:30-40.

Lopreiato, J. e Treanor, J. Lancet, 360:1.711-2.

Potter W. L.

$$
2002
$$

Schlafly, P.

$$
1999
$$

Souza, L. C.

$$
1972
$$

Taylor, B.; Miller, E.;

'Infantile spasms and early immunization against whooping cough'. Archives of Disease in Childhood, 52:134-7.

Manual de vigilância epidemiológica dos eventos adversos pós-vacinação. Fundação Nacional de Saúde.

'Mercury concentrations and metabolism in infants receiving vaccines containing thiomersal: a descriptive study'.

'Measles, mumps, and rubella vaccination and bowel problems or

developmental regression in children with autism: population study'.

Simmons, A. e Stowe, J. $\quad$ British Medical Journal, 324:393-6.

Taylor, B.; Miller, E.; Farrington, C. P.;

Petropoulos, M. C.;

Favot-Mayaud, I. e

Li, J. Waight

$$
1999
$$

The Scientist

United States General Accounting Office

'Autism and measles, mumps and rubella vaccine: no epidemiological evidence for a causal association'.

Lancet, 353:2.026-29.

US Department of

Health, Education

and Welfare

'The MMR saga: blinding or fooling the public with science?'. Obtido em www.biomedcentral.com/news/20010124/03.

'Childhood vaccines: ensuring an adequate supply poses continuing challenges'. Report to Congressional Requesters, setembro de 2002.

Documento obtido em http://www.gao.gov.

Veterinary Public Health Notes, August 1979, p. 1. 
Wakefield, A. J.; 'Ileal lymphoid nodular hyperplasia, non-specific colitis, and regressive Murch, S. H.; Anthony, A.; developmental disorder in children'.

Linnell, J.; Casson, D. M.; $\quad$ Lancet, 351:637-641.

Malik, M.; Berelowitz, M.;

Dhillon, A. P.;

Thomson, M. A.;

Harvey, P.; Valentine, A.;

Davies, S. E. e

Walker-Smith, J. A.

1998

Williamson D. Estudo

'Media unintentionally distorting hazards of child vaccines, causing fear, litigation, danger'. Documento obtido em www.eurekalert.org/pub-releases/ 1996-12.

World Health

Organization

2001

World Health

Organization

'Mumps virus vaccines'.

Weekly Epidemiological Record, 76:346-55.

Yahoo News

'Report of the overview of vaccine research in WHO and UNAIDS, Geneva, 1999'. Documento disponível em http://www.who.ch/gpv-documents.

'MMR blunder puts 40.000 at risk'.

Obtido em http://uk.news.yahoo.com/030708/80/e3wro.html. 